\title{
CHICKEN SKIN GELATINE AS AN ALTERNATIVE TO PORK AND BEEF GELATINES
}

\author{
Petr Mrázek, Pavel Mokrejš, Robert Gál, Jana Orsavová
}

\begin{abstract}
Poultry meat-processing industry produces considerably large amounts of by-products (such as chicken skins, heads, feathers, viscera, bones and legs) containing significant volumes of proteins, particularly collagen. One of the possibilities of advantageous utilization of these under-used by-products can be their application as a raw material rich in collagen for preparation of gelatine, a partial hydrolysate of collagen. In the present study, chicken skins obtained as a by-product from the chicken-breast processing were purified from non-collagen proteins, pigments and fats. Collagen was treated with proteolytic enzymes and the gelatine extraction was performed in distilled water at temperatures of $40,50,60,70$ and $80{ }^{\circ} \mathrm{C}$ during the constant extraction time of $60 \mathrm{~min}$. The influence of the technological conditions on gelatine functional properties including viscosity, clarity, water holding and fat binding capacity, emulsifying and foaming properties was explored. Certain functional properties of prepared gelatines were significantly affected by the extraction temperature, while on some other properties the extraction temperature had no significant effect. Viscosity of prepared chicken skin gelatines was in the range from 3 to $5.7 \mathrm{mPa} . \mathrm{s}^{-1}$, clarity from 1.5 to $2 \%$, water holding capacity from 3.8 to $5.6 \mathrm{~mL} \cdot \mathrm{g}^{-1}$, fat binding capacity from 0.9 to $1.3 \mathrm{~mL} \cdot \mathrm{g}^{-1}$, emulsion capacity from 35 to $50 \%$, emulsion stability from 73 to $88 \%$, foaming capacity from 18 to $61 \%$ and finally foaming stability was from 4 to $39 \%$. Chicken skin gelatines were compared with commercial food grade pork and beef gelatines. Prepared chicken skin gelatines showed better viscosity, fat binding capacity and foaming stability than mammalian gelatines, while water holding capacity, emulsifying stability and foaming capacity were not as good as in beef and pork gelatines. Emulsifying capacity was comparable with commercial gelatines. Therefore, chicken skin gelatine has the potential as an alternative to traditional gelatines from mammalian sources, such as pork or beef bones and skins.
\end{abstract}

Keywords: chicken skin; collagen; food grade gelatine; functional properties; poultry by-products

\section{INTRODUCTION}

Extensive manufacture of poultry meat produces large amounts of by-products such as viscera, feet, heads, bones, blood, feathers or skins (Zhu et al., 2010). These byproducts are normally composted or used for the production of livestock feed. Unfortunately, a common practise in some developing countries is unfortunately to landfill or incinerate them. On the other hand, in some countries poultry by-products, such as heads, paws and stomachs, are cooked, fried and consumed as traditional meals (Toldra, Mora and Reig, 2016). Poultry byproducts are rich in proteins, enzymes and lipids (Ockerman and Hansen, 2000; Raju, Rose and Rao, 1997) and thus possess nutritional and economic potential (Salminen and Rintala, 2002).

Traditional sources of collagen for the production of gelatines are skins, connective tissues and bones from beef or pork origin (Morrison et al., 1999). Gelatine gained from pig skin accounts $46 \%$ of the production, from beef skin $29 \%$, from bones $23 \%$ and $2 \%$ accounts gelatine made from other sources (Ahmad and Benjakul, 2011). Pork gelatine is prohibited to use in Kosher and Halal foods, whereas beef gelatine cannot be consumed by Hindus (Kaewruang et al., 2013). That is why, alternative sources of collagen, such as fish bones, skins and scales, are becoming more important. Another alternative source can also be poultry by-products including chicken, turkey or duck skin. It is estimated that chicken skins represents about $15 \%$ of live weight of the animal (Sheu and Chen, 2002). Thus, chicken skins should be considered as byproducts with significant economic potentional. One of the further options of the application of chicken skins, byproducts from the conversion of chicken meat to chicken breast, is to use it as a raw material for gelatine extraction.

Gelatine is a partial hydrolysate of collagen with a wide range of potential functions based on its specific structure 
(Norziah et al., 2009). This unique biopolymer supply elasticity, viscosity and stability in foods (Zhou, Mulvaney and Regenstein, 2006). Gelatine gel has the ability of "melt in the mouth" which gelatinous agents of plant origin, such as starch, alginate, pectin, agar and carrageenan lack (Bazawine and He, 2003). If the concentration of gelatine solution is suitable for network forming, transition from sol to gel occurrs (Kaur et al., 2002). Gelatine is, due to its unique properties, used as a food ingredient in various types of products to modify e.g. elasticity, slicability and cohesion, (for example in desserts, lunch meats, aspics, marshmallows, ice creams, coating, puddings, sauces, yogurts), in the biomedical field (e.g. wound dressing and three-dimensional tissue regeneration products) or in numerous non-food applications (e.g. photography, paper manufacture, matches, coating, sizing) (Chatterjee and Bohidar, 2005; GMIA, 2012; Petrášová et al., 2016). Gelatine also finds its application in the pharmaceutical industry in the production of soft and hard capsules (Karim and Bhat, 2008). The global consumption of gelatine in 2011 was 348,000 tons and in 2018 it was expected to be as much as 450,000 tons (Sheela, 2014).

Gelatine quality is determined mainly by gelatine gel strength expressed in the Bloom value (Binsi et al., 2009). Further functional characteristics of gelatine including viscosity, clarity, water holding and fat binding capacity, emulsifying and foaming properties are also important, mainly in the food industry.

Viscosity of gelatine and other protein solutions depends on internal characteristics, such as molecular weight, amino acid content or surface charge (Masuelli, 2011). Several studies devoted to viscosity of gelatine solutions have been published recently. Masuelli and Sansone (2012) studied intrinsic viscosity of gelatine. Qiao et al. (2013) determined viscosity of gelatine in solutions of monovalent and divalent salts.

Clarity of gelatine gel may be a significant feature in products which are required to be transparent (Bower et al., 2006). It is an important organoleptic property and determines mainly acceptability of final products (Zarai et al., 2012). Clarity is the opposite of turbidity. Turbidity is influenced by inorganic, protein and mucosubstance contaminants which remain in gelatine unless they have been completely removed during the gelatine preparation.

Water holding capacity (WHC) is the elemental gelatine characteristic and desirable property in food products including sausages, custards and dough because it is supposed to draw water without dissolving proteins and thus attaining products thickening and viscosity. The ability of gelatine to bind water is one of the most significant properties, which is benefitial in numerous food applications. WHC is an important feature for reducing water losses and juiciness of frozen fish or meat products while they are being cooked (Rawdkuen, Thitipramote and Benjakul, 2013). Better WHC may be connected with a higher quantity of hydrophilic groups and affected by many factors, such as a protein concentration and ionic strength (Kinsella, 1976; Li, Jia and Yao, 2009; Ninan, Joseph and Aliyamveettil, 2014). Higher WHC is also related with desired rheological and textural characteristics and reduction in dehydration during the storage (Simões et al., 2014).
Fat binding capacity (FBC) is required property in minced meat formulations helping retain flavour and palatability and prolong the shelf life of baked goods, soups and meat products (Rawdkuen, Thitipramote and Benjakul, 2013). FBC is a significant functional property specifically important in the production of meat and confectionary products (Souissi et al., 2007) as it determines the ability of collagen to bind fat through nonpolar chains of macromolecules (Bhaskaracharya, Kentish and Ashokkumar, 2009). FBC of proteins is related to hydrophobicity of the surface and to the level of exposure of hydrophobic residues inside gelatine molecule. It may be influenced by various factors, such as a type of protein and degree of hydrolysis (George, Joseph and Zynudheen, 2010; Kristinsson and Rasco, 2000).

Emulsifying capacity (EC) and emulsifying stability (ES) of gelatine are especially utilized in the cosmetic industry during the preparation of ointments and creams. Kinsella (1976) defined EC of gelatine as the volume of oil that can be emulsified by gelatine and hydrolysates. Gelatines and hydrolysates are surface active substances and encourage to form oil-in-water emulsions since they are soluble in water and have functional groups both hydrophilic and hydrophobic (Wilding, Lilliford and Regenstein, 1984). It is generally presumed that emulsifying properties of gelatines/hydrolysates are probably affected by difference in their peptide composition, molecular size and lipophilic-hydrophilic arrangement (Li, Jia and Yao, 2009). Gelatines with high gelatine gel strength improves emulsifying properties if they are added to final products (Gómez-Guillén et al., 2011).

The capability of forming stable gelatine foam is crucial in the preparation of confectionery products including marshmallows or other whipped products. This may be explained by probable presence of a large molecules of peptides in chicken skin collagen which can form stable films around gas bubbles (Souissi et al., 2007). In order to create a stable foam on water-air interface, molecules must contain hydrophobic regions that appear during the unfolding of proteins (Gómez-Guillén et al., 2011). Foaming properites of gelatine may be important in the bakery industry as they help to stabilize foaming products, such as pies, breads and cakes (Djagny, Wang and Xu, 2001).

\section{The aims of this study}

This paper continues in the previous research of authors focusing on designing of the proper technological conditions for the chicken skin gelatine preparation, testing the effects of the extraction temperature on gelatine gel strength.

The aims of this paper are as follows:

1. Preparation of chicken skin gelatines at different extraction temperatures according to the method described in the previous work Mrázek et al. (2019 - in press).

2. Testing of functional properties of chicken skin gelatines in relation to food applications: viscosity, clarity, water holding and fat binding capacity, emulsifying capacity and stability and foaming capacity and stability. 
3. Comparison of functional properties of gelatine prepared from chicken skin with commercial food grade pork and beef gelatines.

4. Evaluation of extraction conditions affecting the functional properties of prepared gelatines.

\section{Scientific hypotheses}

There were presumptions that technological conditions during the extraction of gelatines (e.g. temperature) affect the functional properties of prepared gelatines and that functional properties of chicken skin gelatines will be comparable with functional properties pork and beef gelatines.

\section{MATERIAL AND METHODOLOGY}

\section{Appliances, tools and chemicals}

Stevens LFRA Texture Analyser for measuring gelatine gel strength (Leonard Farnell and Co ltd., England), SPAR Mixer SP-100AD-B meat grinder (TH Industry RD, Taiwan), Rotina 35 centrifuge (Hettich, Germany), IKA T 25 digital Ultra-Turray desintegrator (IKA-Werke, Germany), Memmert ULP 400 drying device (Memmert GmbH+Co. KG, Germany), LT 43 shaker (Nedform, Czech Republic), Kern 440-47 electronic scale, Kern 770 electronic analytical balance (Kern, Germany), A 10 labortechnik analytical mill (IKA-Werke, Germany), ULP 400 drying oven (Memmert GmbH+Co. KG, Germany), Samsung fridge-freezer (Samsung, South Korea), Thermo Haake C 10 thermometer (Thermo Fisher Scientific, USA), Helios Epsilon spectrophotometer (Thermo Fisher Scientific, USA), Whatman No. 1 paper (Sigma Aldrich, UK), a metal filter sieve with the size of pores 1 and $2 \mathrm{~mm}$ (Labor-komplet, Czech Republic). Chemicals: $\mathrm{NaCl}, \mathrm{NaOH}$, petroleum ether, ethanol and chloroform (Verkon, Czech Republic); all chemicals were of analytical grade. Proteolytic enzyme Polarzyme 6.0 T-serine endoprotease manufactured by fermentation of microorganisms that are not present in the final product (Novozymes, Denmark) with declared enzyme activity of 6 KPU.g ${ }^{-1}$ (kilo protease unit. $\mathrm{g}^{-1}$ ). Commercial gelatines, pork DO12119 260 Bloom (type A) and beef D529 260 Bloom (type B) of the grain size of $2 \mathrm{~mm}$. Virgin sunflower oil (Via Naturae, Czech Republic).

\section{Preparation of chicken skin gelatines}

Chicken skins were purchased from Raciola (Uherský Brod, Czech Republic). The composition of chicken skins was as follows: dry matter: $53.6 \pm 1.5 \%$; in dry matter: proteins: $16.5 \pm 1.3$, collagen: $92.6 \pm 0.1$, fats: $85.0 \pm 2.4$, inorganic solids: $0.9 \pm 0.3$ (Davídek et al., 1981; ISO 3496-1994). The raw material was processed into gelatines according to the method described in Mrázek et al. (2019 - in press). The raw material was ground to the size of particles of $3 \mathrm{~mm}$ and separation of non-collagen parts was performed using $1 \mathrm{M} \mathrm{NaCl}$ and $0.5 \% \mathrm{NaOH}$. After filtration and rinsing with water, raw material was dried at $35^{\circ} \mathrm{C}$. Separation of fats was performed using the mixture of solvents of petroleum ether and ethanol at the ratio of 1:1 (w/w). The filtration process was followed by proteolytic enzyme pre-treatment using $0.5 \%$ Polarzyme 6.0T in distilled water at $\mathrm{pH}$ 7.5. After filtration and rinsing with water, 5 experiments of gelatine extraction were realized in distilled water at 40,50, 60, 70 and $80 \pm 0.5{ }^{\circ} \mathrm{C}$ for $60 \mathrm{~min}$. After filtration of gelatine solution using Whatman no.1 paper (Sigma Aldrich, UK) and drying it in a thin layer at $45{ }^{\circ} \mathrm{C} \pm 0.3{ }^{\circ} \mathrm{C}$. Gelatine powder was prepared by grinding of the gelatine film to the size of particles of $1-2 \mathrm{~mm}$ using A 10 labortechnik analytical mill (IKA-Werke, Germany). Samples of gelatines were then subjected to further analysis.

\section{Testing of functional properties of gelatines}

Prepared gelatine samples were analysed in order to compare the functional properties of gelatines produced under different extraction temperatures. Results were compared with the analyses of two types of commercial food grade gelatines (pork and beef).

\section{Viscosity}

Viscosity of gelatine solution was measured according to the method described at GMIA (2013). $6.67 \%$ gelatine solution was prepared as follows: $7.5 \mathrm{~g}$ of gelatine was mixed with $105 \mathrm{~mL}$ of distilled water and maintained at room temperature for $2 \mathrm{~h}$ in order to swell. The sample was afterwards dissolved in $65^{\circ} \mathrm{C}$ water bath for not more than $10 \mathrm{~min}$. Gelatine solution was transferred to the viscosity pipette placed inside thermometer Thermo Haake C 10 (Thermo Fisher Scientific, USA). The temperature of $60.00 \pm 0.05^{\circ} \mathrm{C}$ was maintained. Time required for $100 \mathrm{~mL}$ of gelatine solution to pass through the capillary tube of the pipette by draining gelatine solution was measured. Viscosity of gelatine sample was calculated from the following equation:

$$
v=k \cdot t-\frac{B}{t}
$$

$v$ - kinematic viscosity $\left[\mathrm{mm}^{2} . \mathrm{s}^{-1}\right]$

$\mathrm{k}$ - the viscosity constant detected by calibration fluid $(0.5)$

$\mathrm{t}-$ arithmetic mean of measured flow times [s]

B - correction constant for kinetic energy determined from dimensions of the viscometer (2.8)

Kinematic viscosity was converted to dynamic viscosity according to the following equation:

$$
\eta=v \cdot \rho
$$

$\eta$ - dynamic viscosity [mPa.s]

$\rho-$ gelatin solution density $\left[\mathrm{g} . \mathrm{cm}^{-3}\right]$

Density of gelatine was $1.003 \mathrm{~g} . \mathrm{cm}^{-3} \pm 0.005$ and it was determined by pycnometric method.

\section{Clarity}

Clarity of gelatine solution was determined according to the method described at GMIA (2013). The same gelatine solution as for viscosity measurement was used. It was heated at the temperature of $45{ }^{\circ} \mathrm{C}$ in water bath and transmittance value at $\lambda=640 \mathrm{~nm}$ using Helios Epsilon spectrophotometer (Thermo Fisher Scientific, USA) was recorded. 


\section{Water holding capacity}

Water holding capacity (WHC) was determined in conformity with the method described by Nasrin, Noomhorm and Anal (2015). Gelatine sample (1 g) was weighed and dispersed in $25 \mathrm{~mL}$ of distilled water in test tube by vortexing for $5 \mathrm{~min}$ at room temperature. After that, it was centrifuged using Rotina 35 centrifuge (Hettich, Germany) at 3,000 rpm for $30 \mathrm{~min}$. Supernatant was filtered with Whatman no. 1 paper and the sample was then weighed again.

Water holding capacity was calculated using a formula:

$$
W H C=\frac{w_{1}}{w_{0}}
$$

WHC - water holding capacity [mL.g-1 ${ }^{-1}$

$\mathrm{w}_{1}$ - weight of sample after analysis $[\mathrm{g}]$

$\mathrm{w}_{0}-$ weight of sample before analysis $[\mathrm{g}]$

\section{Fat binding capacity}

Fat binding capacity (FBC) was determined according to the method by Li, Jia and Yao (2009). Gelatine sample $(0.1 \mathrm{~g})$ was weighed and dispersed in $10 \mathrm{~mL}$ sunflower oil in test tubes and properly mixed by vortexing for $1 \mathrm{~min}$ and allow to stand for $30 \mathrm{~min}$ at room temperature. Afterwards, gelatine was dispersed in oil and centrifuged at 3,000 rpm for $30 \mathrm{~min}$. Free oil was decanted and FBC was calculated using the following formula:

$$
F B C=\frac{w_{1}}{w_{0}}
$$

FBC - water holding capacity $\left[\mathrm{mL} . \mathrm{g}^{-1}\right]$

$\mathrm{w}_{1}$ - weight of sample after analysis $[\mathrm{g}]$

$\mathrm{w}_{0}$ - weight of sample before analysis $[\mathrm{g}]$

\section{Emulsifying properties}

Emulsifying capacity and stability were determined according to the method by Neto et al. (2001). $5 \mathrm{~mL}$ of gelatine solution (prepared by heating at $45{ }^{\circ} \mathrm{C}$ ) at concentration of $10 \mathrm{mg} \cdot \mathrm{mL}^{-1}$ was homogenized with $5 \mathrm{~mL}$ of sunflower oil for $1 \mathrm{~min}$. Thereafter, the mixture of gelatine and oil was centrifuged at 1,100 rpm for $5 \mathrm{~min}$. Emulsifying capacity was determined using the following formula:

$$
E C=\frac{H_{1}}{H_{0}} \cdot 100
$$

EC - emulsifying capacity [\%]

$\mathrm{H}_{1}$ - height of emulsion layer [mm]

$\mathrm{H}_{0}$ - height of the total content [mm]

After that the emulsion of fat and gelatine was heated in $55^{\circ} \mathrm{C}$ water bath followed by centrifugation at $1,100 \mathrm{rpm}$ for 5 min. Emulsifying stability was calculated using the formula:

$$
E S=\frac{H_{1}}{H_{0}} \cdot 100
$$

ES - emulsifying stability [\%]

$\mathrm{H}_{1}$ - height of emulsion layer after heating [mm]

$\mathrm{H}_{0}$ - height of emulsion layer before heating [mm]

\section{Foaming properties}

Foaming capacity and foaming stability were determined according to the method by Sathe, Deshpande and Salunkhe (1982). $0.6 \mathrm{~g}$ of gelatine and $30 \mathrm{~mL}$ distilled water was mixed and heated at $60{ }^{\circ} \mathrm{C}$. Foam was prepared by homogenization

10,000 rpm for 5 min using IKA T 25 Digital Ultra-Turray desintegrator (IKA-Werke, Germany).

Foamed gelatine solution was poured into $250 \mathrm{~mL}$ measuring cylinder and foaming capacity was calculated using the formula:

$$
F C=\frac{V_{1}-V_{0}}{V_{0}} \cdot 100
$$

$\mathrm{FC}$ - foaming capacity [\%]

$\mathrm{V}_{1}$ - volume of foamed liquid $[\mathrm{mL}]$

$\mathrm{V}_{0}$ - initial volume of liquid [mL]

Thereafter foaming stability was determined. The principle was based on measuring the volume of foamed gelatine solution after $30 \mathrm{~min}$; foaming stability was calculated according to the following formula:

$$
F S=\frac{V_{2}-V_{0}}{V_{0}} \cdot 100
$$

FS - foaming stability [\%]

$\mathrm{V}_{2}$ - volume of foamed liquid after $30 \mathrm{~min}$

$\mathrm{V}_{0}$ - initial volume of liquid [mL]

\section{Statistical analysis}

All analyses were performed in triplicate; linear regression, 1-sample and 2 -sample t-test testing on the significance level of $\mathrm{p} 0.05$ were applied to all results using Minitab 18 statistical software for Windows (Minitab 213 Inc., USA).

\section{RESULTS AND DISCUSSION}

\section{Testing of functional properties of chicken skin gelatines}

Tables 1 and 2 show obtained values of viscosity, clarity, water holding capacity (WHC), fat binding capacity (FBC) emulsifying capacity (EC), stability (ES), foaming capacity (FC) and stability (FS) of gelatines prepared at different extraction temperatures.

\section{Viscosity}

The relationship between viscosity and extraction temperature is not statistically significant $(\mathrm{p}>0.05)$. Viscosity moderately decline with an increasing extraction temperature as can be seen in Figure 1. It plummet from $50{ }^{\circ} \mathrm{C}$ to $60{ }^{\circ} \mathrm{C}$. At $60{ }^{\circ} \mathrm{C}$ the values reached the minimum. 
Table 1 Viscosity, clarity, water holding capacity (WHC) and fat binding capacity (FBC) of prepared chicken skin gelatines at different extraction temperatures. CSG - chicken skin gelatines.

\begin{tabular}{|c|c|c|c|c|}
\hline $\begin{array}{l}\text { CSG } \\
\left({ }^{\circ} \mathbf{C}\right)\end{array}$ & $\begin{array}{c}\text { Viscosity } \\
(\mathrm{mPa} . \mathrm{S} \pm \mathrm{SD})\end{array}$ & $\begin{array}{c}\text { Clarity } \\
(\% \pm \text { SD })\end{array}$ & $\begin{array}{c}\text { WHC } \\
\left(\mathrm{mL}^{-\mathrm{g}^{-1}} \pm \mathrm{SD}\right)\end{array}$ & $\begin{array}{c}\text { FBC } \\
\left(\mathrm{mL} \cdot \mathrm{g}^{-1} \pm \mathrm{SD}\right)\end{array}$ \\
\hline 40 & $5.2 \pm 1.51$ & $1.51 \pm 0.51$ & $3.85 \pm 0.30$ & $0.97 \pm 0.20$ \\
\hline 50 & $4.4 \pm 1.87$ & $1.95 \pm 0.75$ & $3.99 \pm 0.15$ & $1.15 \pm 0.25$ \\
\hline 60 & $2.7 \pm 0.14$ & $1.45 \pm 0.35$ & $4.59 \pm 0.19$ & $1.26 \pm 0.22$ \\
\hline 70 & $3.0 \pm 0.15$ & $1.61 \pm 0.31$ & $5.00 \pm 0.19$ & $1.06 \pm 0.07$ \\
\hline 80 & $5.7 \pm 0.12$ & $1.95 \pm 0.55$ & $5.58 \pm 0.18$ & $0.87 \pm 0.08$ \\
\hline$p$-value & 0.939 & 0.558 & 0.002 & 0.622 \\
\hline
\end{tabular}

Table 2 Emulsifying capacity (EC) and stability (ES) and foaming capacity (FC) and stability (FS) of prepared chicken skin gelatines at different extraction temperatures. CSG - chicken skin gelatines.

\begin{tabular}{ccccc}
\hline $\begin{array}{c}\text { CSG } \\
\left({ }^{\circ} \mathbf{C}\right)\end{array}$ & $\begin{array}{c}\text { EC } \\
(\boldsymbol{\%} \pm \text { SD) }\end{array}$ & $\begin{array}{c}\text { ES } \\
(\boldsymbol{\%} \pm \text { SD })\end{array}$ & $\begin{array}{c}\text { FC } \\
(\boldsymbol{\%} \pm \mathbf{S D})\end{array}$ & $\begin{array}{c}\text { FS } \\
(\boldsymbol{\%} \pm \text { SD })\end{array}$ \\
\hline 40 & $50.00 \pm 7.86$ & $72.50 \pm 3.54$ & $48.89 \pm 1.92$ & $38.89 \pm 9.91$ \\
50 & $43.27 \pm 1.65$ & $87.50 \pm 0.85$ & $35.56 \pm 3.85$ & $33.33 \pm 3.25$ \\
60 & $37.50 \pm 5.89$ & $81.67 \pm 2.36$ & $17.78 \pm 5.09$ & $8.89 \pm 6.94$ \\
70 & $36.84 \pm 0.87$ & $85.71 \pm 0.91$ & $20.00 \pm 5.77$ & $4.44 \pm 5.09$ \\
80 & $35.09 \pm 2.48$ & $84.52 \pm 1.68$ & $61.11 \pm 9.62$ & $5.56 \pm 9.62$ \\
$p$-value & 0.019 & 0.290 & 0.904 & 0.030 \\
\hline
\end{tabular}

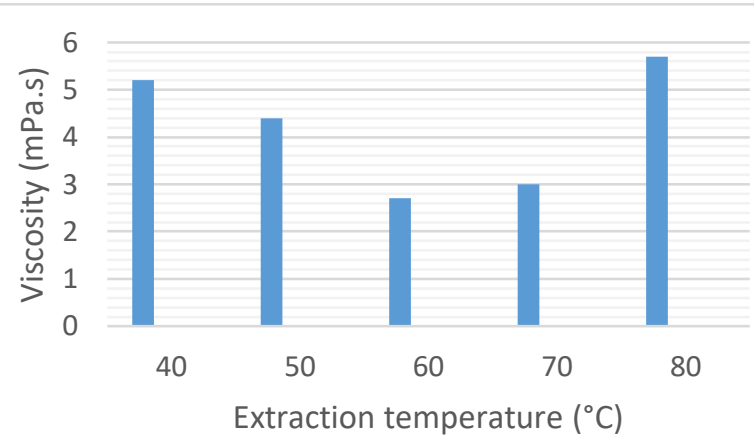

Figure 1 Viscosity of chicken skin gelatines prepared at different extraction temperatures.

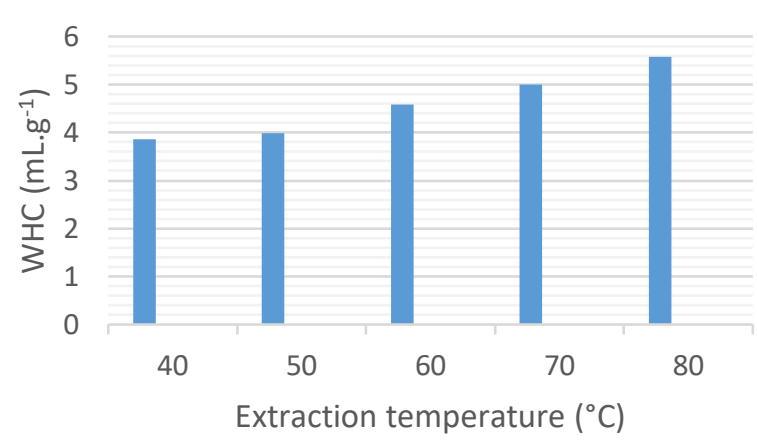

Figure 3 Water holding capacity (WHC) of chicken skin gelatines prepared at different extraction temperatures.

An upward trend is observed between the extraction temperatures of $60{ }^{\circ} \mathrm{C}$ and $70{ }^{\circ} \mathrm{C}$. However, at $80{ }^{\circ} \mathrm{C}$ viscosity soar slightly above the level registered at $40{ }^{\circ} \mathrm{C}$. Viscosity of gelatine solutions is the highest at the extraction temperature of $80{ }^{\circ} \mathrm{C}$ and lowest at $60{ }^{\circ} \mathrm{C}$. This

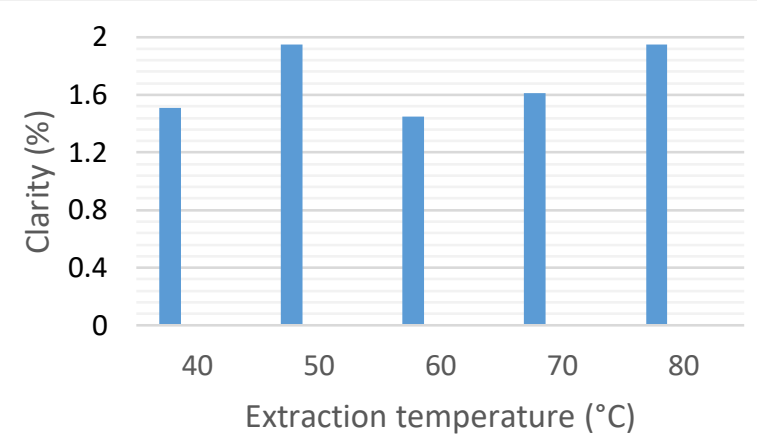

Figure 2 Clarity of chicken skin gelatines prepared at different extraction temperatures.

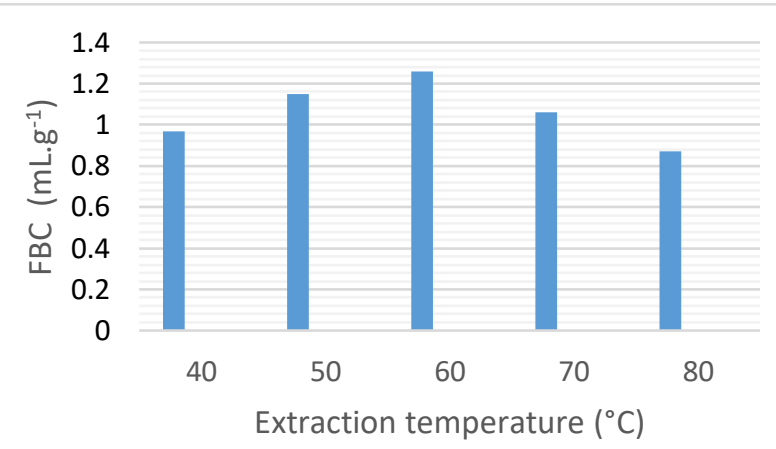

Figure 4 Fat binding capacity (FBC) of chicken skin gelatines prepared at different extraction temperatures.

may be explained by the fact that at the temperature of $60{ }^{\circ} \mathrm{C}$ the level of hydrolysis is the highest and collagen chains have the lowest molecular mass resulting in lower viscosity. This assumption was proved by the highest 
gelatine yield recorded at this extraction temperature in the previous study Mrázek et al. (2019 - in press).

Ninan, Joseph and Aliyamveettil (2014) anounced viscosity of grass carp skin gelatine of $7.07 \mathrm{mPa}$.s. Rafieian, Keramat and Kadivar (2011) reported viscosity of chicken gelatine from deboner of $5.85 \mathrm{mPa}$.s. Bichukale et al. (2018) stated that viscosity of poultry skin and bone ranged from 3.83 to $9.10 \mathrm{mPa}$.s. Therefore, viscosity of prepared chicken skin gelatines is comparable with data obtained in other studies.

\section{Clarity}

No significant influence of the extraction temperature on clarity has been observed $(p>0.05)$. As depicted in Figure 2 , clarity values is in a range from 1.5 to $1.9 \%$ which represents very low level of clarity. This may be attributed to residual impurities in gelatine. Mad-Ali et al. (2017) reported turbidity of gelatine solution from 1.8 to $2 \%$ depending on drying method.

\section{Water holding capacity (WHC)}

The effect of extraction temperature on WHC is statistically significant $(p<0.05)$. WHC increases almost linearly with an increasing extraction temperature as Figure 3 depicts $\left(\mathrm{R}^{2}=97.23\right)$. WHC of gelatine has been extensively examined during the last few years. Omar and Sarbon (2016) studied the effect of drying method on functional properties and antioxidant activities of chicken skin gelatine hydrolysate and recorded WHC values from

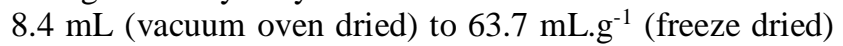
depending on drying method and $\mathrm{pH}$ of gelatine. Dhakal et al. (2018) investigated optimal conditions of collagen extraction from chicken feet by papain hydrolysis and synthesis of chicken feet collagen based biopolymeric fibres and determined WHC of $1.9 \mathrm{~mL} . \mathrm{g}^{-1}$. Surangna and Anal (2016) discussed the optimization of extraction of functional protein hydrolysates from chicken egg shell membrane (ESM) by ultrasonic assisted extraction (UAE) and enzymatic hydrolysis and reported values of WHC varying from 1.9 to $2.9 \mathrm{~mL} . \mathrm{g}^{-1}$ depending on the type of pre-treatment. Therefore, prepared gelatines analysed in this study are similar to these results.

\section{Fat binding capacity}

The relationship between $\mathrm{FBC}$ and extraction temperature is not statistically significant $(p>0.05)$. As can be seen in Figure 4, FBC rises with an increasing extraction temperature until reaches the peak at $60{ }^{\circ} \mathrm{C}$; then it decreases to a slightly lower value than it was observed at $40{ }^{\circ} \mathrm{C}$. This may stem from the fact that at the extraction temperature of $60{ }^{\circ} \mathrm{C}$ the rate of hydrolysis is the highest resulting in more hydrophobic residues exposed for bonding with fat molecules. Several studies have been proceeded in order to determine FBC of gelatine. Li, Jia and Yao (2009) examined amino acid composition and functional properties of collagen polypeptide from Yak (Bos grunniens) bone and reported FBC of only 0.21 to $0.29 \mathrm{~mL} \cdot \mathrm{g}^{-1}$. Surangna and Anal (2016) determined FBC from 2.5 to $4.4 \mathrm{~mL}^{-1}$ and Dhakal et al. (2018) reported FBC of $5.3 \mathrm{~mL} . \mathrm{g}^{-1}$ which is in accordance with the results of this study.

\section{Emulsifying capacity and stability (EC and ES)}

The influence of extraction temperature on EC is statistically significant $(p<0.05)$. Figure 5 shows that there is a decrease of EC between the extraction temperatures of $40{ }^{\circ} \mathrm{C}$ and $60^{\circ} \mathrm{C}$. However, EC remains nearly steady from $60{ }^{\circ} \mathrm{C}$ to $80{ }^{\circ} \mathrm{C}$. This trend may be caused by changes in gelatine structure affected by the temperature rise.

The mean of ES were significantly higher than the mean of $\mathrm{EC}(p<0.001)$. ES soars between the extraction temperatures of $40{ }^{\circ} \mathrm{C}$ and $50{ }^{\circ} \mathrm{C}$ and fluctuate from $50{ }^{\circ} \mathrm{C}$ to $80{ }^{\circ} \mathrm{C}$. The highest emulsifying capacity and stability was recorded at the extraction temperatures of $40{ }^{\circ} \mathrm{C}$ and $50{ }^{\circ} \mathrm{C}$, respectively. Several studies have been conducted to determine emulsifying properties. Li, Jia and Yao (2009) studied amino acid composition and functional properties of collagen polypeptide from Yak (Bos grunniens) bone and stated EC of yak bone collagen of $57.3 \%$ which is slightly higher than EC of chicken skin gelatine extracted at $40{ }^{\circ} \mathrm{C}$. Shahidi, Xiao-Qing, Synowiecki (1995) investigated production and characteristics of protein hydrolysates from Capelin (Mallotus-villosus) and reported EC of lyophilized capelin protein hydrolysates of $50.9 \%$ and ES of $92 \%$ which is comparable with the present study. Omar and Sarbon (2016) examined the effect of drying method on functional properties and antioxidant activities of chicken skin gelatin hydrolysate and registered EC and ES of chicken skin gelatine of approx. 56\% which is very similar to the results by Li, Jia and Yao (2009).

\section{Foaming capacity and stability (FC and FS)}

The relationship between FC and extraction temperature is not statistically significant $(p>0.05)$. Figure 6 shows that between the extraction temperatures of 40 and $60{ }^{\circ} \mathrm{C}$ there is a steep decrease of FC. From $60{ }^{\circ} \mathrm{C}$ to $70{ }^{\circ} \mathrm{C}$ it remained steady followed by a dramatic soar between $70{ }^{\circ} \mathrm{C}$ and $80{ }^{\circ} \mathrm{C}$. This thermal behaviour can be explained by the fact that the level of hydrolysis is probably the highest at the temperature of $60{ }^{\circ} \mathrm{C}$ (as it was mentioned previously); therefore, collagen molecules contain shorter chains and are unable to form a stable foam.

The mean of FS is not significantly different from the mean of FC ( $p=0.141$ ); however, the effect of extraction temperature on FS is statistically significant $(p<0.05)$. FS values were slightly lower at $50{ }^{\circ} \mathrm{C}$ compared to $\mathrm{FC}$; however, decrease of FS is more obvious at 40,60 and 70 ${ }^{\circ} \mathrm{C}$ in comparison with $\mathrm{FC}$ and the extreme difference was recorded at $80{ }^{\circ} \mathrm{C}$. It is obvious that an increasing temperature causes a decline in FS. The most appropriate extraction temperature for the best foaming properties seems to be $40{ }^{\circ} \mathrm{C}$ due to the significantly high $\mathrm{FC}$ value and highest FS value. Several studies have been performed in order to investigate foaming properties.

Haddar et al. (2011) studied physicochemical and functional properties of gelatin from tuna (Thunnus thynnus) head bones and reported FC from 64 to $80 \%$ and FS from 41 to $60 \%$ depending on the concentration of gelatine. Jain and Anal (2016) investigated optimization of extraction of functional protein hydrolysates from chicken egg shell membrane (ESM) by ultrasonic assisted extraction (UAE) and enzymatic hydrolysis and reported FC of protein hydrolysate prepared from eggshell 
Table 3 Comparison of viscosity, water holding capacity (WHC), fat binding capacity (FBC), clarity of chicken skin gelatine extracted at $40^{\circ} \mathrm{C}$ with commercial food grade pork and beef gelatines.

\begin{tabular}{ccccc}
\hline & Viscosity $(\mathbf{m P a . s} \pm$ SD) & WHC $\left(\mathbf{m L . g}^{-\mathbf{1}} \pm\right.$ SD) & FBC $\left(\mathbf{m L} . \mathbf{g}^{-\mathbf{1}} \pm\right.$ SD $)$ & Clarity $(\% \pm$ SD $)$ \\
\hline CSG & $5.2 \pm 1.51$ & $3.85 \pm 0.30$ & $0.97 \pm 0.20$ & $1.51 \pm 0.51$ \\
PG & $2.4 \pm 0.05$ & $4.43 \pm 0.26$ & $0.42 \pm 0.11$ & $65.33 \pm 0.47$ \\
BG & $3.5 \pm 0.17$ & $6.42 \pm 0.26$ & $0.71 \pm 0.06$ & $86.17 \pm 4.31$ \\
\hline
\end{tabular}

Note: CSG - chicken skin gelatine extracted at $40{ }^{\circ} \mathrm{C} ; \mathrm{PG}$ - commercial food grade pork gelatine; $\mathrm{BG}$ - commercial food grade beef gelatine.

Table 4 Comparison of emulsifying capacity (EC), emulsifying stability (ES), foaming capacity (FC) and foaming stability (FS) of chicken skin gelatine extracted at $40{ }^{\circ} \mathrm{C}$ with commercial food grade pork and beef gelatines.

\begin{tabular}{ccccc}
\hline & EC $(\% \pm$ SD) & ES $(\% \pm$ SD $)$ & FC $(\% \pm$ SD $)$ & FS $(\% \pm$ SD $)$ \\
\hline CSG & $50.00 \pm 7.86$ & $72.50 \pm 3.54$ & $48.89 \pm 1.92$ & $38.89 \pm 9.71$ \\
PG & $30.67 \pm 4.04$ & $94.44 \pm 9.62$ & $62.23 \pm 3.87$ & $14.40 \pm 1.91$ \\
BG & $57.67 \pm 4.04$ & $88.89 \pm 9.91$ & $55.10 \pm 1.71$ & $13.17 \pm 0.23$ \\
\hline
\end{tabular}

Note: CSG - chicken skin gelatine extracted at $40{ }^{\circ} \mathrm{C}$; PG - commercial food grade pork gelatine; BG - commercial food grade beef gelatine.

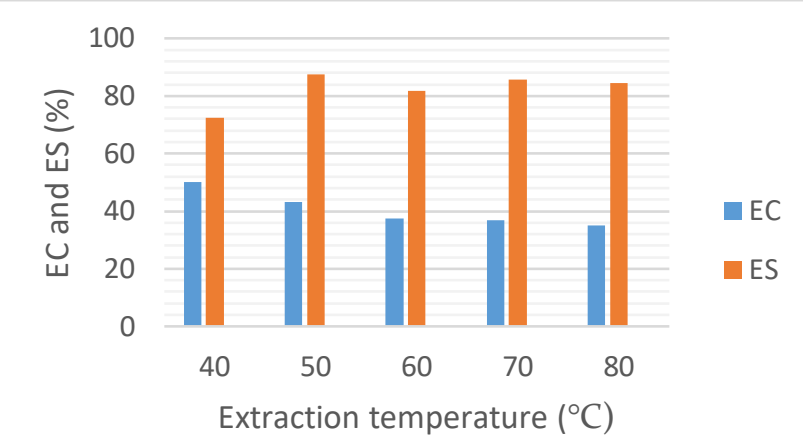

Figure 5 Emulsifying capacity (EC) and stability (ES) of chicken skin gelatines prepared at different extraction temperatures.

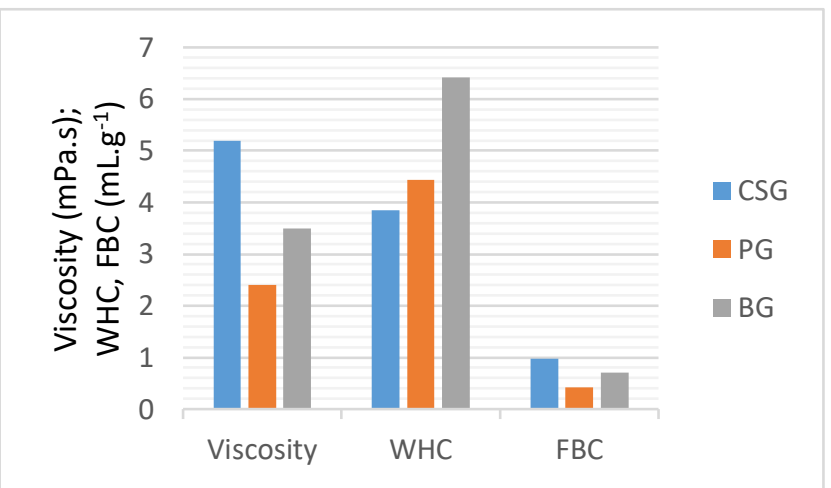

Figure 7a Comparison of viscosity, water holding capacity (WHC) and fat binding capacity (FBC) of chicken skin gelatine (CSG) prepared at $40{ }^{\circ} \mathrm{C}$ with commercial pork (PG) and beef (BG) gelatine.

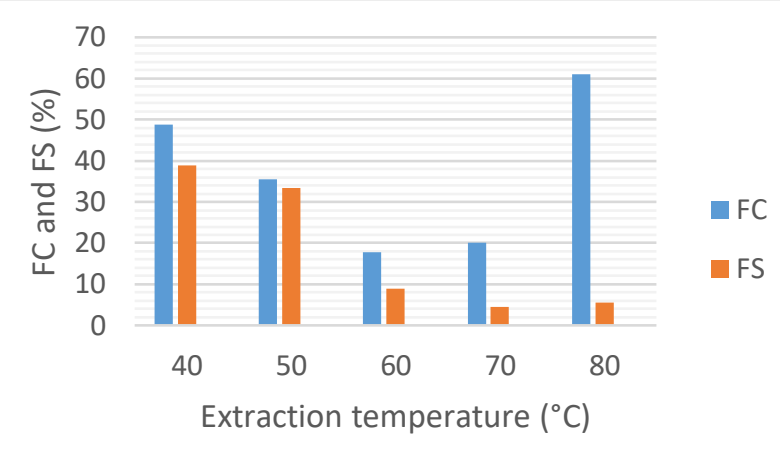

Figure 6 Foaming capacity (FC) and stability (FS) of chicken skin gelatines prepared at different extraction temperatures.

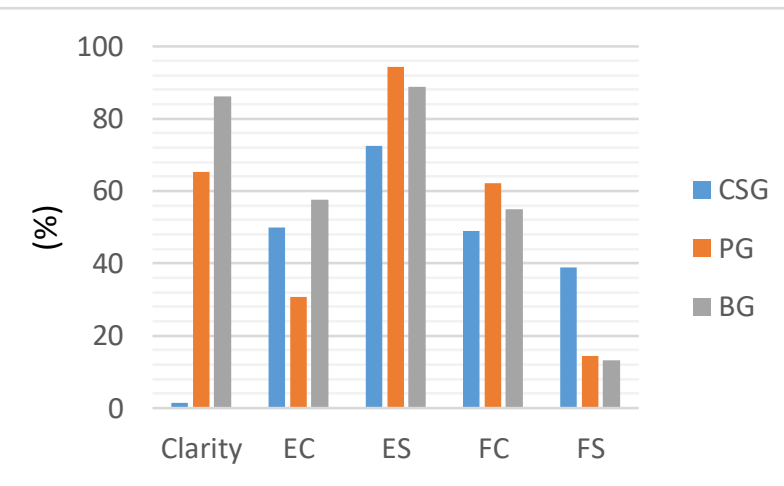

Figure 7b Comparison of clarity, emulsifying capacity (EC), emulsifying stability (ES), foaming capacity (FC) and foaming stability (FS) of chicken skin gelatine (CSG) prepared at $40{ }^{\circ} \mathrm{C}$ with commercial pork (PG) and beef (BG) gelatine.

hydrolysis and synthesis of chicken feet collagen based biopolymeric fibres and reported FC of $16.7 \%$ and FS of $11.7 \%$ which is in accordance with the results of this study. membrane in the range from $21.7 \%$ to $28.3 \%$ and FS from 8.3 to $25 \%$ depending on the applied method of preparation. Dhakal et al. (2018) examined optimization of collagen extraction from chicken feet by papain 


\section{Comparison of functional properties of chicken skin gelatines with commercial food grade pork and beef gelatine}

The mean of viscosity of chicken skin gelatines (CSG) is significantly higher than the viscosity of pork gelatine $(p<0.05)$, whereas it is not significantly different in comparison with viscosity of beef gelatine $(p>0.05)$. The mean of clarity of CSG is significantly less than the viscosity of pork and beef gelatines $(p<0.05)$. The mean of WHC of CSG is not significantly different from WHC of pork gelatine $(p>0.05)$; however in contrast to beef gelatine it is significantly less $(p<0.05)$. The mean of FBC of CSG is significantly greater than WHC of pork and beef gelatines $(p<0.05)$. The mean of EC of CSG is significantly greater than EC of pork gelatine $(p<0.05)$, while the mean of EC of CSG is significantly less than EC of beef gelatine $(p<0.05)$. The mean of ES of CSG is significantly lower than ES of pork gelatine $(p<0.05)$, however the mean of ES of CSG is not significantly different from ES of beef gelatine $(p>0.05)$. The mean of FC of CSG is significantly less than FC of pork and beef gelatines $(p<0.05)$. The mean of FS of CSG is not significantly different from FS of pork and beef gelatines $(p>0.05)$.

Gelatine extracted at the temperature of $40{ }^{\circ} \mathrm{C}$ was chosen for the illustration of comparison with commercial food grade beef and pork gelatine because this gelatine has the highest gel strength as described in the previous study, (Mrázek et al., 2019 - in press), emulsifying capacity, foaming capacity and stability, and significantly high viscosity of all prepared samples. Tables 3 and 4, Figures $7 \mathrm{a}$ and $7 \mathrm{~b}$ display obtained data. Viscosity of prepared chicken skin gelatine is higher by $53 \%$ and $31 \%$ than viscosity of pork and beef gelatine, respectively. WHC of chicken skin gelatine is lower by $67 \%$ and $15 \%$ than WHC of beef and pork gelatine, respectively. FBC of prepared gelatine is higher by $57 \%$ and $27 \%$ than FBC of pork and beef gelatine, respectively. On the other hand, clarity of prepared gelatin is considerably lower than clarity of pork and beef gelatine. This may be attributed to difficulty in the cleaning process in laboratory conditions. EC of chicken skin gelatine is $15 \%$ lower than EC of beef gelatine whereas it is by $39 \%$ higher than the value of pork gelatine, which are comparative results. ES of chicken skin is 30\% lower than ES of pork gelatine and 23\% lower than beef gelatine. FC of prepared gelatine is lower by $27 \%$ and $13 \%$ than FC of pork and beef gelatine, respectively; while FS is higher by $63 \%$ and $66 \%$ than FS of pork and beef gelatine, respectively, which are excellent results. In addition, FS is 4.3 times lower than FC in commercial gelatines, whereas only 1.3 times lower in prepared chicken skin gelatine. This may be ascribed to the difference in intrinsic properties and composition of proteins in various gelatine sources (Damodaran, 2005).

\section{CONCLUSION}

Chicken skin gelatines were prepared by extraction in distilled water at 5 different temperatures of 40, 50, 60, 70 and $80{ }^{\circ} \mathrm{C}$ at constant extraction time of $60 \mathrm{~min}$. Functional properties of gelatines (viscosity, clarity, water holding capacity, fat binding capacity, emulsifying capacity/stability and foaming capacity/stability) were investigated. Results revealed that the extraction temperature has an influence on the properties of gelatine. With respect to the highest emulsifying capacity, foaming stability and high viscosity of gelatine, the extraction temperature of $40{ }^{\circ} \mathrm{C}$ appears to the most appropriate; in addition, this gelatin has the highest gel strength. The most suitable extraction temperature for the highest viscosity, water holding capacity and foaming capacity was $80^{\circ} \mathrm{C}$; however, for the highest fat binding capacity it was $60{ }^{\circ} \mathrm{C}$ and for emulsion stability $50{ }^{\circ} \mathrm{C}$.

Functional properties of chicken skin gelatine extracted at $40{ }^{\circ} \mathrm{C}$ were compared with those of commercial food grade pork and beef gelatine. Viscosity, fat binding capacity and foaming stability of chicken skin gelatine were higher in comparison with mammalian gelatines. Water holding capacity, emulsifying stability and foaming capacity of chicken skin gelatine were lower than those of mammalian gelatines. Clarity of chicken skin gelatines were significantly lower than clarity of mammalian gelatines; this will be a subject of the following research. All tested gelatines showed comparable emulsifying capacity.

The results of experiments have proven that it is possible to prepare chicken skin gelatine with comparable functional properties to food grade beef and pork gelatine. Chicken skin gelatine has a promising potential to be an alternative to mammalian gelatines.

\section{REFERENCES}

Ahmad, M., Benjakul, S. 2011. Characteristics of Gelatin from the Skin of Unicorn Leatherjacket (Aluterus monoceros) as Influenced by Acid Pretreatment and Extraction Time. Food Hydrocolloids, vol. 3, no. 3, p. 25-34. https://doi.org/10.1016/j.foodhyd.2010.07.004

Bazawine, D., He, Q. 2003. Gelatin: The Paramount food additive. Food Reviews International, vol. 19, no. 4, p. 423435. https://doi.org/10.1081/FRI-120025483

Bhaskaracharya, R. K., Kentish, S., Ashokkumar, M. 2009. Selected Applications of Ultrasonics in Food Processing. Food Engineering Reviews, vol. 1, no. 1, p. 31-49. https://doi.org/10.1007/s12393-009-9003-7

Bichukale, A. D., Koli, J. M., Sonavane, A. E., Vishwasrao, V. V., Pujari, K. H., Shingare, P. E. 2018. Functional Properties of Gelatin Extracted From Poultry Skin and Bone Waste. International Journal of Pure \& Applied Bioscience, vol. 6, no. 4, p. 87-101. https://doi.org/10.18782/2320$\underline{7051.6768}$

Binsi, P. K., Shamasundar, B. A., Dileep, A. O., Badii, F., Howell, N. K. 2009. Rheological and Functional Properties of Gelatin from the Skin of Bigeye Snapper (Priacanthus Hamrur) Fish. Food Hydrocolloids, vol. 23, no. 1, p. 132-145. https://doi.org/10.1016/j.foodhyd.2007.12.004

Bower, C. K., Avena-Bustillos, R. J, Olsen, C. W, McHugh, T. H, Bechtel, P. J. 2006. Characterization of Fish-Skin Gelatin Gels and Films Containing the Antimicrobial Enzyme Lysozyme. Journal of Food Science, vol. 71, no. 5, p. 141145. https://doi.org/10.1111/j.1750-3841.2006.00031.x

Chatterjee S., Bohidar, H. B. 2005. Effect of Cationic Size on Gelation Temperature and Properties of Gelatin Hydrogels. International Journal of Biological Macromolecules, vol. 35 , no. $1-2, \quad$ p. 81-88. https://doi.org/10.1016/j.ijbiomac.2005.01.002

Damodaran, S. 2005. Protein Stabilization of Emulsions and Foams. Journal of Food Science and technology, vol. 70, no. 
3, p. 54-65. https://doi.org/10.1111/j.13652621.2005.tb07150.x

Davídek, J., Hrdlička, J., Karvánek, M., Pokorný, J., Seifert, J., Velíšek, J. 1981. Laboratory guide of food analysis. (Laboratorni príručka analýzy potravin). Prague, Czech Republic : SNTL. 718 p. (in Czech)

Dhakal, D., Koomsap, P., Lamichhane, A., Sadiq, M. B., Anal, A. K. 2018. Optimization of Collagen Extraction From Chicken Feet by Papain Hydrolysis and Synthesis of Chicken Feet Collagen Based Biopolymeric Fibres. Food Bioscience, vol. 23, no. 1, p. 23-30. https://doi.org/10.1016/j.fbio.2018.03.003

Djagny, K. B., Wang, Z., Xu, S. 2001. Gelatin: a Valuable Protein for Food and Pharmaceutical Industries: Review. Critical Reviews in Food Science and Nutrition, vol. 4, no. 6, p. 481-492. https://doi.org/10.1080/20014091091904

GMIA. 2012. Gelatin Handbook. Available at: http://www.gelatin-

gmia.com/images/GMIA_Gelatin_Manual_2012.pdf

GMIA. 2013. Standard Testing Methods for Edible Gelatin. Available at: http://www.gelatingmia.com/images/GMIA_Official_Methods_of_Gelatin_Revi sed_2013.pdf

Gómez-Guillén, M. C., Giménez, B., López-Caballero, M. E., Montero, M. P. 2011. Functional and Bioactive Properties of Collagen and Gelatin from Alternative Sources: Review. Food Hydrocolloids, vol. 25, no. 8, p. 1813-1827. https://doi.org/10.1016/j.foodhyd.2011.02.007

George, N., Joseph, J., Zynudheen, A. 2010. Physical, Mechanical, and Barrier Properties of Carp and Mammalian Skin Gelatin Films. Journal of Food Science, vol. 75, no. 9, p. 620-626. https://doi.org/10.1111/j.1750-3841.2010.01851.x

Haddar, A., Bougatef, A., Balti, R., Souissi, N., Koched, W., Nasri, M. 2011. Physicochemical and Functional Properties of Gelatin from Tuna (Thunnus Thynnus) Head Bones. Journal of Food and Nutrition Research, vol. 50, no. 3, p. $150-159$.

ISO 3496: 1994. Meat and meat products -- Determination of hydroxyproline content

Jain, S., Anal, A., K. 2016. Optimization of Extraction of Functional Protein Hydrolysates from Chicken Egg Shell Membrane (Esm) by Ultrasonic Assisted Extraction (Uae) and Enzymatic Hydrolysis. LWT - Food Science and Technology, vol. 69, no. 1, p. 295-302. https://doi.org/10.1016/j.lwt.2016.01.057

Kaewruang, P., Benjakul, S., Prodpran, T., Nalinanon, S. 2013. Physicochemical and Functional Properties of Gelatin from the Skin of Unicorn Leatherjacket (Aluterus Monoceros) as Affected by Extraction Conditions. Food Bioscience, vol. 2, no. 1, p. 1-9. https://doi.org/10.1016/j.fbio.2013.03.002

Karim, A., Bhat, R. 2008. Gelatin Alternatives for the Food Industry: Recent Developments, Challenges and Prospects. Trends in Food Science \& Technology, vol. 12, no. 12, p. 644-656. https://doi.org/10.1016/j.tifs.2008.08.001

Kaur, M., Jumel, K., Hardie, K. R., Hardman, A., Meadows, J., Melia, C. D. 2002. Determining the Molar Mass of a Plasma Substitute Succinylated Gelatin by Size Exclusion Chromatography -Multi- Angle Laser Light Scattering, Sedimentation Equilibrium and Conventional Size Exclusion Chromatography. Journal of Chromatography A, vol. 957, no. 2, p. 139-148. https://doi.org/10.1016/S0021-9673(02)00350$\underline{3}$

Kinsella, J. E. 1976. Functional Properties of Proteins in Foods: a Survey. Critical Reviews in Food Science \& Nutrition, vol. 8, no. 3, p. 219-280. https://doi.org/10.1080/10408397609527208
Kristinsson, H. G., Rasco, B. A. 2000. Biochemical and Functional Properties of Atlantic Salmon (Salmo Salar) Muscle Proteins Hydrolyzed with Various Alkaline Proteases. Journal of Agricultural and Food Chemistry, vol. 48, no. 3, p. 657-666. https://doi.org/10.1021/jf990447v

Li, F., Jia, D., Yao, K. 2009. Amino acid composition and functional properties of collagen polypeptide from Yak (Bos grunniens) bone. LWT-Food Science and Technology, vol. 42, no. 5, p. 945-949. https://doi.org/10.1016/j.lwt.2008.12.005

Mad-Ali, S., Benjakul, S., Prodpran, T., Maqsood, S. 2017. Characteristics and Gelling Properties of Gelatin from Goat Skin as Affected by Drying Methods. Journal of Food Science and Technology, vol. 54, no. 6, p. 1646-1654. https://doi.org/10.1007/s13197-017-2597-5

Masuelli, M. A. 2011. Viscometric Study of Pectin. Effect of Temperature on the Hydrodynamic Properties. International Journal of Biological Macromolecules, vol. 48, no. 2, p. 286-291. https://doi.org/10.1016/j.ijbiomac.2010.11.014

Masuelli, M. A., Sansone, M. G. 2012. Hydrodynamic Properties of Gelatin. Studies from Intrinsic Viscosity Measurements, In Verbeek, C. J. R (Ed.). Products and Applications of Biopolymers., InTech, p. 85-116. ISBN 978953-51-0226-7.

Morrison, N. A., Sworn, G., Clark, R. C., Chen, Y. L., Talashek, T. 1999. Gelatine Alternatives in the Food Industry. In Nishinari K. (eds). Physical Chemistry and Industrial Application of Gellan Gum. Heidelberg: Springer Verlag, p. 127-131. ISBN 978-3-540-48349-6. https://doi.org/10.1007/3540-48349-7_19

Mrázek, P., Mokrejš, P., Gál, R., Orsavová, J. 2019. Assessment of possibilities of food grade gelatines preparation from chicken skin. In Mendelnet Conference, Brno, Czech Republic: Mendelnet University Brno, in press.

Nasrin, T. A. A., Noomhorm, A., Anal, A. K. 2015. Physico-chemical characterization of culled plantain pulp starch, peel starch and flour. International Journal of Food Properties, vol. 18, no. 1, p. 165-177. https://doi.org/10.1080/10942912.2013.828747

Neto, V. Q., Narain, N., Silva, J. B., Bora, P. S. 2001. Functional Properties of Raw and Heat Processed Cashew Nut (Anarcardium occidentale L.) Kernel Protein Isolates. Nahrung/Food, vol. 45, no. 4, p. 258-262. https://doi.org/10.1002/1521-3803(20010801)45:4<258::AIDFOOD258>3.0.CO;2-3

Ninan, G., Joseph, J., Aliyamveettil, Z. 2014. A Comparative Study on the Physical, Chemical and Functional Properties of Carp Skin and Mammalian Gelatins. Journal of Food Science and Technology, vol. 51, no. 9, p. 2085-2091. https://doi.org/10.1007/s13197-012-0681-4

Norziah, M. H, Al-Hassan, A., Khairulnizam, A. B., Mordi, M. N., Norita, M. 2009. Characterization of Fish Gelatin from Surimi Processing Wastes. Food Hydrocolloids, vol. 23, no. 6, p. 1610-1616. https://doi.org/10.1016/j.foodhyd.2008.12.004

Ockerman, H. W., Hansen, C. L. 2000. Animal By-Product Processing \& Utilization. Lancaster: Technomic Pub. Co. 544 p. ISBN 1566767776.

Omar, W., Sarbon, N. 2016. Effect of Drying Method on Functional Properties and Antioxidant Activities of Chicken Skin Gelatin Hydrolysate. Journal of Food Science and Technology, vol. 53, no. 11, p. 3928-3938. https://doi.org/10.1007/s13197-016-2379-5

Petrášová, M., Zichová, E., Pospiech, M., Tremlová, B., Javůrková, Z. 2016. Possibilities of Microscopic Detection of Isolated Porcine Proteins in Model Meat Products. 
Potravinarstvo, vol. 10, no. $1, \quad$ p. 202-206. https://doi.org/10.5219/588

Qiao, C., Chen, G., Li, Y., Li, T. 2013. Viscosity Properties of Gelatin in Solutions of Monovalent and Divalent Salts. Korea-Australia Rheology Journal, vol. 25, no. 4, p. 227-231. https://doi.org/10.1007/s13367-013-0023-8

Rafieian, F., Keramat, J., Kadivar, M. 2011. Optimization of Gelatin Extraction from Chicken Deboner Residue Using RSM Method. Journal of food science and technology, vol. 50, no. 2, p. 374-80. https://doi.org/10.1007/s13197-0110355-7

Raju, A. A., Rose, C., Rao, N. M. 1997. Enzymatic Hydrolysis of Tannery Fleshings Using Chciken intestine Proteases. Animal Feed Science and technology, vol. 66, no.14, p. 139-147. https://doi.org/10.1016/S0377-8401(96)01109$\underline{1}$

Rawdkuen, S., Thitipramote, N., Benjakul, S. 2013. Preparation and Functional Characterisation of Fish Skin Gelatin and Comparison with Commercial Gelatin. International Journal of Food Science \& Technology, vol. 48, no. 5, p. 1093-1102. https://doi.org/10.1111/ijfs.12067

Salminen, E. A., Rintala, J. 2002. Anaerobic Digestion of Organic Solid Poultry Slaughterhouse Waste - a Review. Bioresource Technology, vol. 83, no. 1, p. 13-26. https://doi.org/10.1016/S0960-8524(01)00199-7

Sathe, S. K., Deshpande, S. S., Salunkhe, D. K. 1982. Functional properties of lupin seed (Supinus mutabilis) proteins and protein concentrates. Journal of Food Science, vol. 7, no. 2, p. 191-197. https://doi.org/10.1111/j.13652621.1982.tb10110.x

Shahidi, F., Xiao-Qing, H., Synowiecki, J. 1995. Production and characteristics of protein hydrolysates from Capelin (Mallotus-villosus). Food Chemistry, vol. 53, no. 3, p. 285293. https://doi.org/10.1016/0308-8146(95)93934-J

Sheela, A. K. 2014. Gelatin Market by Raw Material (Pig Skin, Bovine Hide, Bones and Others) for Food \& Beverage, Nutraceuticals, Pharmaceuticals, Photography, Cosmetics and Other Applications - Global Industry Analysis, Size, Share, Growth, Trends and Forecast, 2012-2018. Available at: http://www.transparencymarketresearch.com/gelatin.html

Sheu, K. S., Chen, T. C. 2002. Yield and Quality Characteristics of Edible broiler Skin Fat as Obtained from Five rendering methods. Journal of Food Engineering, vol. 55, no. 3, p. 263-269. https://doi.org/10.1016/S0260$\underline{8774(02) 00100-0}$

Simões, G. S., Silveira, E. T. F., De Oliveira, S. R., Poleze, E., Allison, J. R., Ida, E. I., Shimokomaki, M. 2014. Optimum Conditions for Extracting Collagen from the Tunica Albuginea of Immunologically Castrated Pig Testes and the Functional Properties of the Isolated Collagen. Meat Science, vol. 96, no. 4, p. 1460-1468. https://doi.org/10.1016/j.meatsci.2013.10.038

Souissi, N., Bougatef, A., Triki-Ellouz, Y., Nasri, M. 2007. Biochemical and Functional Properties of Sardinella
(Sardinella aurita) By-product Hydrolysates. Food technology and Biotechnology, vol. 45, no. 2, p. 187-194.

Surangna, J., Anal, A. K. 2016. Optimization of Extraction of Functional Protein Hydrolysates from Chciken Egg Shell membrane (ESM) by Ultrasonic Assisted Extraction (UAE) and Enzymatic Hydrolysis. Food Science and technology, vol. 69, no. 1, p. 295302. https://doi.org/10.1016/j.lwt.2016.01.057

Toldra, F., Mora, L., Reig, M. 2016. New Insights into Meat By-Product Utilization. Meat Science, vol. 120, no. 1, p. 5459. https://doi.org/10.1016/j.meatsci.2016.04.021

Wilding, P., Lilliford, P. J., Regenstein, J. M. 1984. Functional Properties of Proteins in Foods. Journal of Chemical Technology and Biotechnoogy, vol. 34, no. 3, 182 p. https://doi.org/10.1002/jctb.280340307

Zarai, Z., Balti, R., Mejdoub, H., Gargouri, Y., Sayari, A. 2012. Process for Extracting Gelatin from Marine Snail (Hexaplex Trunculus): Chemical Composition and Functional Properties. Process Biochemistry, vol. 47, no. 12, p. 17791784. https://doi.org/10.1016/j.procbio.2012.06.007

Zhou, P., Mulvaney, S. J., Regenstein, J. M. 2006. Properties of Alaska Pollock Skin Gelatin. Journal of Food Science, vol. 71, no. 6, p. 313-321. https://doi.org/10.1111/j.1750-3841.2006.00065.X

Zhu, G. Y., Zhu, X., Wan, X. L., Fan, Q., Ma, Y. H., Qian, J., Liu, X. L., Shen., Y. J., Jiang, J. H. 2010. Hydrolysis Technology and Kinetics of Poultry Waste to Produce Amino Acids in Subcritical Water. Journal of Analytical and Applied Pyrolysis, vol. 88, no. 2, p. 187-191. https://doi.org/10.1016/j.jaap.2010.04.005

\section{Acknowledgments:}

The research was financially supported by the Internal Grant Agency of the Faculty of Technology, Tomas Bata University in Zlín, ref. IGA/FT/2019/003.

\section{Contact address:}

*Petr Mrázek, Tomas Bata University in Zlín, Faculty of technology, Department of Polymer Engineering, Vavrečkova 275, 760 01, Zlín, Czech Republic, Tel.: +420576031331, E-mail: p_mrazek@utb.cz

Pavel Mokrejš, Tomas Bata University in Zlín, Faculty of technology, Department of Polymer Engineering, Vavrečkova 275, 760 01, Zlín, Czech Republic, Tel.: +420576031230, E-mail: mokrejs@utb.cz

Robert Gál, Tomas Bata University in Zlín, Faculty of technology, Department of Food Technology, Vavrečkova 275, 76001 Zlín, Czech Republic, Tel.: +420576033006, E-mail: gal@utb.cz

Jana Orsavová, Tomas Bata University in Zlín, Faculty of Humanities, Language Centre, Štefánikova 5670, 760 01 Zlín, Czech Republic, Tel.: +420576038 158, E-mail: orsavova@utb.cz

Corresponding author: * 